\title{
Observed and projected changes in the annual cycle of Southern Hemisphere baroclinicity for storm formation
}

\author{
Frederiksen, C.S. $^{\text {a }}$, J.S. Frederiksen ${ }^{\text {b }}$, J.M. Sisson ${ }^{\text {a }}$ and S.L. Osbrough ${ }^{\text {b }}$ \\ ${ }^{a}$ Centre for Australian Weather and Climate Research, Bureau of Meteorology, Docklands, Victoria, \\ Australia \\ ${ }^{\mathrm{b}}$ Centre for Australian Weather and Climate Research, CSIRO Marine and Atmospheric Research, \\ Aspendale, Victoria, Australia
}

Email: c.frederiksen@bom.gov.au

\begin{abstract}
Recent studies have shown that over the last sixty years, there have been dramatic changes in the properties of mid-latitude winter storms which have impacted on southern Australian winter rainfall. In particular, there have been large reductions and negative trends in rainfall over this period, associated with similar reductions in the growth rates of storm track modes and a preference for some storms to develop further south of the Australian continent. These changes in the properties of mid-latitude storms have been shown to be associated with major shifts in the Southern Hemisphere winter circulation over this period. In particular, there have been significant negative trends in the baroclinic instability of the mid-latitude atmospheric circulation resulting in a reduction in storm formation at these latitudes, while increases in baroclinicity further poleward have led to increased storm development. These effects have become more pronounced with time and are likely to worsen under future climate change scenarios.
\end{abstract}

In this paper, we consider the observed changes in the baroclinicity of Southern Hemisphere circulation in all months. We employ a useful diagnostic of storm development related to baroclinic instability, and encapsulated in the Phillips criterion. The relationship between changes in the Phillips criterion and the implied changes in storm formation and rainfall in all months during the twentieth century is discussed. We find that there are significant negative trends in baroclinicity at mid-latitudes in all months which imply a reduction in storm formation and rainfall at these latitudes. Further poleward, we find significant positive trends associated with increased cyclogenesis and rainfall, in all months. These trends are shown generally to be statistically significant at the $99 \%$ level. Negative trends with values around $-0.15 \mathrm{~ms}^{-1}$ per year occur upstream of Australia, in regions associated with storm formation. Trends further southwards can reach values of $+0.1 \mathrm{~ms}^{-1}$ per year. During May to October, significant negative trends occur in the region of the subtropical jetstream; in November to April, negative trends occur about 10 degrees further south. These trends correspond to reductions of up to $7-8 \mathrm{~ms}^{-1}$ in the mid-latitudes, and increases of about $5 \mathrm{~ms}^{-1}$ at high latitudes, by the end of the twentieth century. This tendency for a reduction in storm development in the midlatitudes, and a greater chance of storm development at higher latitudes, is a consistent feature of each month.

Results from the miroc3_2 high and medium resolution models, which capture many of these changes during the twentieth century, have also been used to examine the projected changes in baroclinicity in SRESA1B and SRESA2 scenarios for the period 2001 to 2099. During May to October, when mid-latitude storms have the biggest impact on southern Australia, we find similar patterns of negative and positive trends in the midlatitudes and high latitudes to those observed and simulated in the twentieth century. Consistent with this result, the projections show hemispheric reductions in rainfall in a band between $10 \mathrm{~S}$ and $40 \mathrm{~S}$ and increases further south. Differences in rainfall, between the periods 1980-1999 and 2080-2099, vary between -40mm to $+40 \mathrm{~mm}$. Over SWWA and southeastern Australia there are reductions in rainfall in all months with differences exceeding $-20 \mathrm{~mm}$ in some months, especially over SWWA.

Keywords: Baroclinic Instability, Mid-latitude Storms, Climate Modelling, Climate Change, Southern Hemisphere Circulation 
Frederiksen et al., Observed and projected changes in the annual cycle of Southern Hemisphere...

\section{INTRODUCTION}

Over the last sixty years there has been a steady downward trend in winter rainfall over much of southern Australia, and especially over southwest Western Australia (SWWA) (Nicholls 2007; Bates et al. 2008; Frederiksen et al., 2010, 2011a, b). In a series of papers, these trends have been associated with large-scale changes in the global atmospheric circulation and the resultant impact on Southern Hemisphere (SH) cyclogenesis, with a reduction in the intensity of storm formation and the southward deflection of some storms (Frederiksen and Frederiksen, 2007, 2011c). Frederiksen et al. (2010, 2011a, b) have related these changes in storm formation, and consequently rainfall, to long term trends in the baroclinic instability of the SH circulation, as measured by the Phillips criterion (Phillips, 1954). Significant negative trends in the Phillips criterion in a hemispheric band between $30 \mathrm{~S}$ - 40S were shown to be consistent with the observed reduction in growth rate of storm development and rainfall decrease in similar latitude bands. Positive trends in instability further southward were shown to be similarly consistent with a tendency for storms to develop in these regions and for increased rainfall. Frederiksen et al. (2010, 2011a, b) also showed, in climate models able to reproduce twentieth century changes, that these trends would continue into the twenty first century with increasing anthropogenic carbon dioxide emissions.

In this paper, we consider the observed changes and trends in the annual cycle of SH baroclinicity and discuss the implications for changes in midlatitude storm formation and $\mathrm{SH}$ rainfall. We also examine projections of possible changes in baroclinic instability under some of the Special Report on Emission Scenarios (SRES) (see, for example, Meehl et al., 2007) using simulations from the high and medium resolution miroc3_2 models. Frederiksen et al. (2010,2011a, b) examined the response of the Coupled Model Intercomparison Project Three (CMIP3) climate models (Meehl et al., 2007) to observed natural and anthropogenic forcing and found that these two models, in particular, were able to capture many of the large scale winter circulation changes observed over the last sixty years.

\section{SOUTHERN HEMISPHERE BAROCLINICITY}

\subsection{Annual Cycle in Baroclinic Instability}

The Phillips (1954) criterion, generalized for spherical geometry, is a simple diagnostic that provides a measure of incipient baroclinic instability and can be used to identify geographical regions of likely cyclogenesis, or storm development (Frederiksen and Frederiksen, 1992). This criterion may be written as

$$
\bar{u}^{(1)}-\bar{u}^{(3)}-\frac{b_{\kappa} c_{p} \bar{\sigma}}{a \Omega} \frac{\left(1-\mu^{2}\right)^{1 / 2}}{\mu^{2}} \geq 0 .
$$

Here, $\bar{u}^{(1)}$ and $\bar{u}^{(3)}$ represent the $300 \mathrm{hPa}$ and $700 \mathrm{hPa}$ zonal velocities, and $\bar{\sigma}$ the static stability for a given basic state, calculated here as half the difference between the potential temperature at $300 \mathrm{hPa}$ and $700 \mathrm{hPa}$.

Also $c_{p}=1004 \mathrm{~J} \mathrm{deg}^{-1} \mathrm{~kg}^{-1}$, is the specific heat of air at constant pressure, $\Omega=7.292 \times 10^{-5} \mathrm{rad} \mathrm{s}^{-1}$, is the earth's angular speed of rotation, $b_{\mathrm{\kappa}}=0.124$ is a dimensionless constant, $a=6.371 \times 10^{6} \mathrm{~m}$, is the radius of the earth and $\mu$ is the sine of latitude. Near the equator, the criterion is always negative and is therefore mostly relevant for the development of extra-tropical, or mid-latitude, cyclogenesis. The more positive the criterion, the more unstable is the atmosphere and leads to the development of faster growing storms. 
(a)

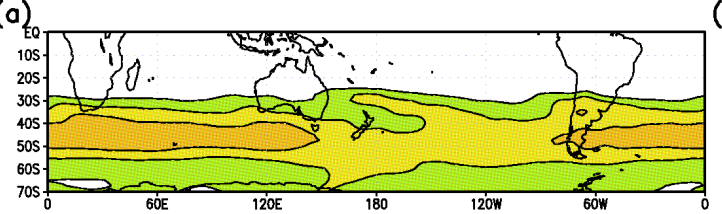

(c)

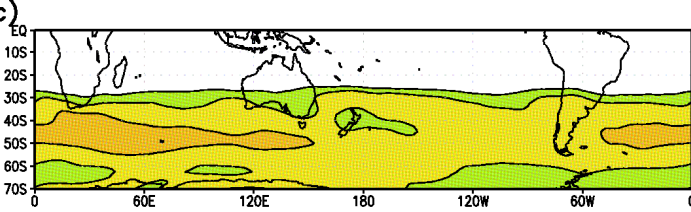

(e)

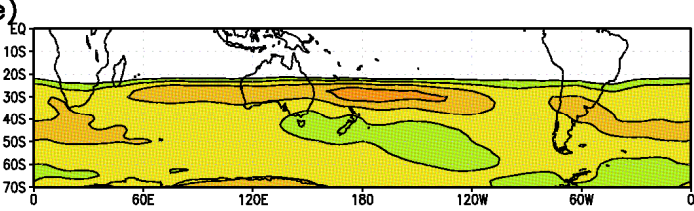

(g)

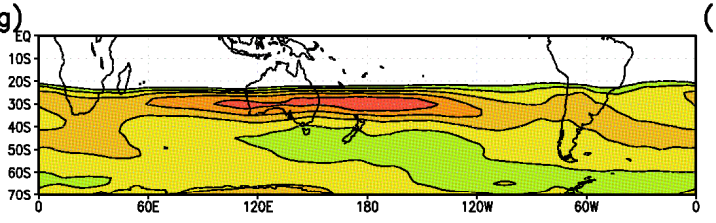

(i)

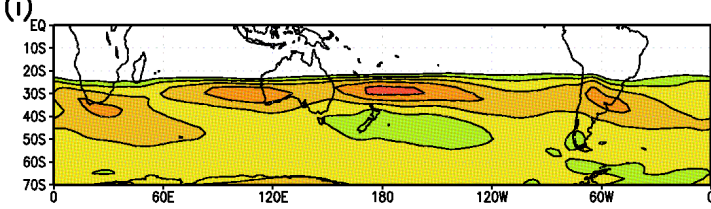

(k)
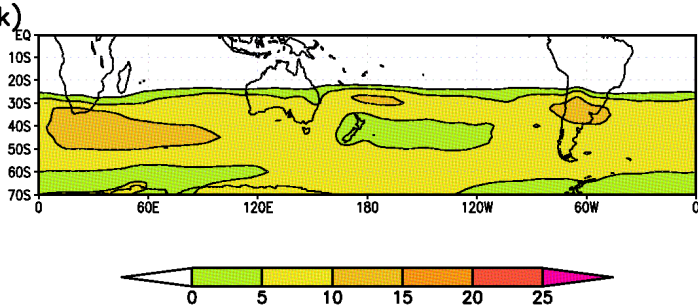

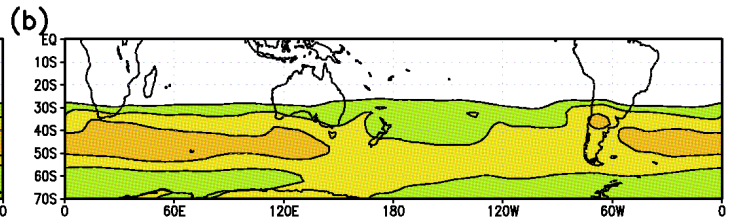

(d)
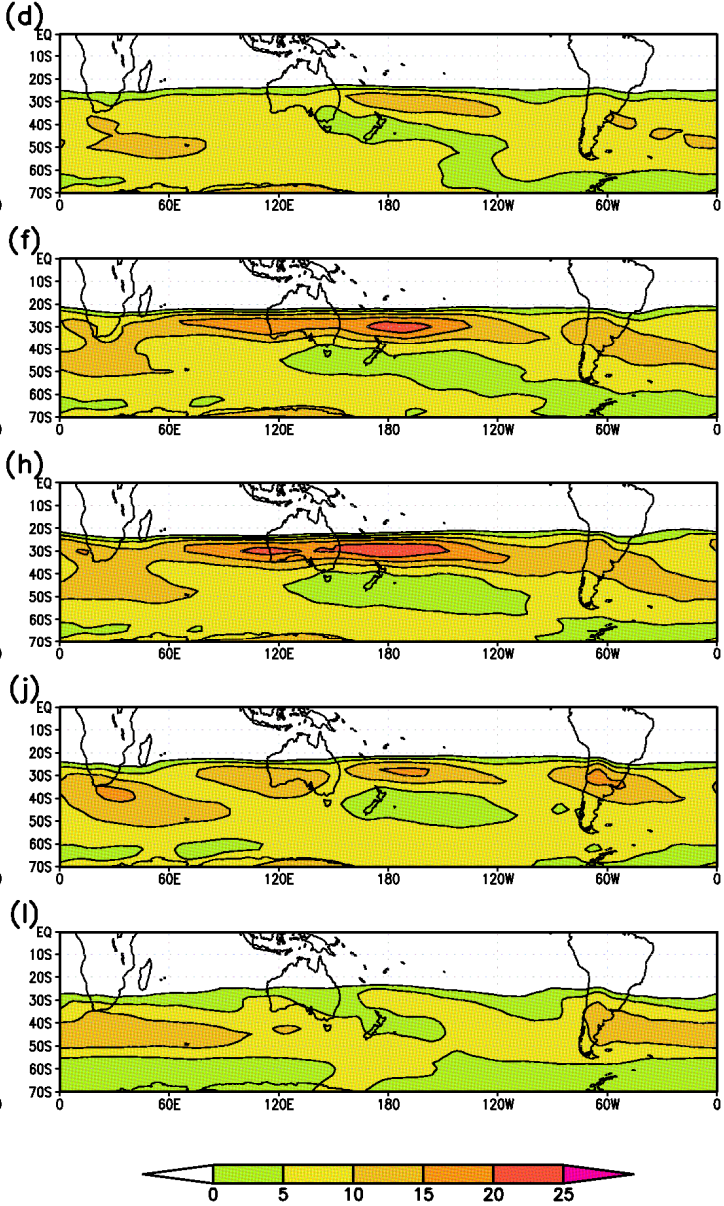

Figure 1. Annual cycle of the Phillips instability criterion $\left(\mathrm{ms}^{-1}\right)$ from NCEP reanalysis averaged over the years 1949-1968 with (a) - (l) corresponding to months January - December.

Figure 1 shows the climatology of the annual cycle of the monthly Phillips criterion using NCEP reanalysis data averaged over the twenty year period 1949-1968. For the six months May - October, large values in the criterion occur upstream and over Australia, and coincident with the location of the subtropical jet near 30S. In the remaining months, November - April, large values occur upstream of Australia between 40S and 50S at latitudes associated with the polar jet. Thus, storms developing upstream during May - October have trajectories more likely to impact on rainfall over southern Australia than those during November - April whose origin of genesis is further south.

\subsection{Observed Trends in Baroclinic Instability}

The continual reduction in the growth rates of mid-latitude storm modes, or weather systems, that affected southern Australia, during the latter half of last century, has been shown to be related to the effective stabilization of the atmosphere at these latitudes (Frederiksen and Frederiksen, 2005, 2007, 2011; Frederiksen et al., 2010, 2011b). Consistent with these results, Frederiksen et al. (2011a) recently showed that the dramatic reduction in July rainfall over southern Australia, and especially SWWA, was associated with statistically significant negative trends in the July Phillips criterion in the region of the subtropical jet, upstream of Australia. Here, we examine trends in baroclinic instability in all months for the period $1950-$ 1999. 
(a)

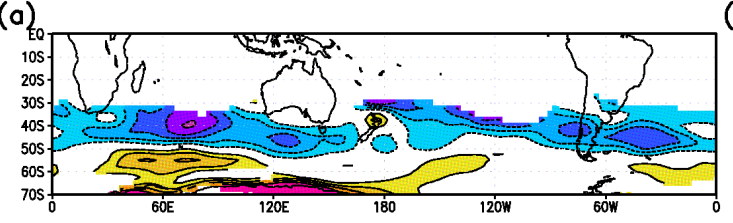

(c)

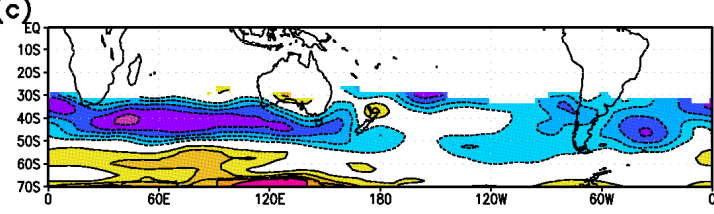

(e)

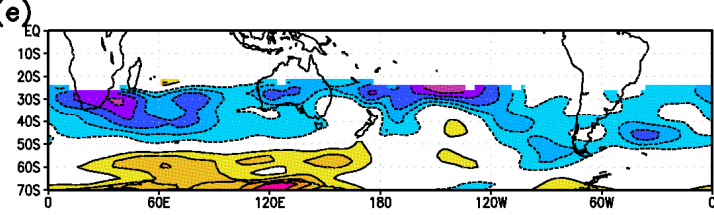

(g)

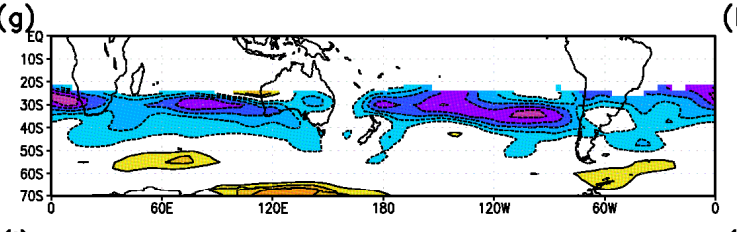

\section{(i)}

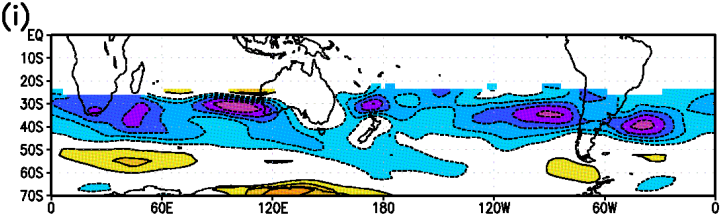

(k)

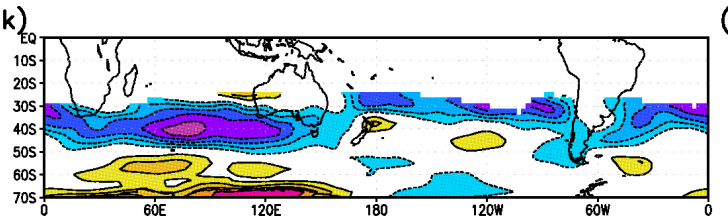

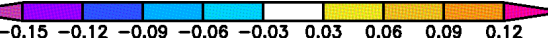
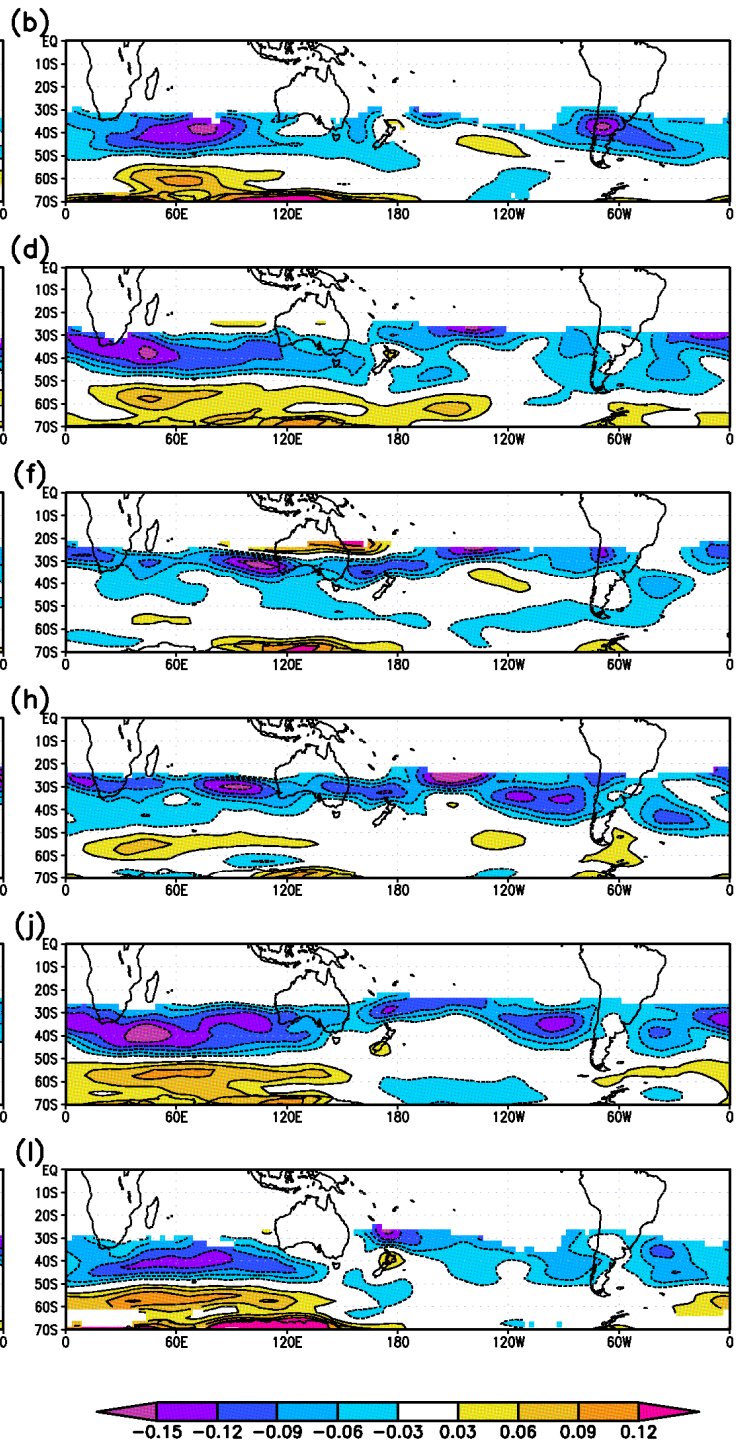

Figure 2. Trends in the Phillips instability criterion $\left(\mathrm{ms}^{-1}\right.$ per year) from NCEP reanalysis for the period 1950 - 1999 with (a) - (l) corresponding to months January - December. Solid lines are positive contours, dotted lines negative contours.

Figure 2 shows the linear trends in the Phillips criterion for each month over this fifty year period. The trends shown in colour are generally statistically significant at the $99 \%$ level, and at least at the $95 \%$ level. In each month, there are negative trends throughout the mid-latitudes of the Southern Hemisphere. Highly significant negative trends, reaching $-0.15 \mathrm{~ms}^{-1}$ per year in some months, occur upstream of Australia, in regions associated with storm formation. Further southwards, there are significant positive trends, with maximum values around $+0.1 \mathrm{~ms}^{-1}$ per year near $60 \mathrm{~S}$. There is a clear annual cycle in the position of the greatest negative trends, with these generally located more equatorward $(25 \mathrm{~S}-305 \mathrm{~S})$ in May - October, and between $35 \mathrm{~S}-50 \mathrm{~S}$ in November - April. Positive trends occur between $50 \mathrm{~S}-70 \mathrm{~S}$ in all months. Over the fifty years, these trends correspond to reductions of up to $7-8 \mathrm{~ms}^{-1}$ in the mid-latitudes, and increases of about $5 \mathrm{~ms}^{-1}$ at high latitudes. Thus, in all months, there is a tendency for a reduction in storm development in the midlatitudes, and a greater chance of storm development at higher latitudes.

Upstream of, and over, the Australian region, inter-annual and decadal variations (not shown) in the Phillips criterion about these trends can have magnitudes of the order of $4 \mathrm{~ms}^{-1}$ and $1.4 \mathrm{~ms}^{-1}$, respectively. The largest variations about the trend line generally occur during May - October. These changes are directly associated with changes in the Hadley circulation including a reduction in the strength of the downward branch near the SH jet core. They are also associated with warming trends in the Southern Ocean showing a similar annual cycle. 
Frederiksen et al., Observed and projected changes in the annual cycle of Southern Hemisphere...

\subsection{Future Projected Trends in Baroclinic Instability}

In this section we discuss projections of possible changes in baroclinic instability under some of the Special Report on Emission Scenarios (SRES) (see, for example, Meehl et al., 2007; Randall, D.A., et al. 2007). The largest impact of mid-latitude storms on southern Australian rainfall occurs during May - October, so we will restrict our analysis to this six month period. Frederiksen et al. (2011a, b) evaluated the performance of the CMIP3 models in simulating the large scale shifts in the Southern Hemisphere July circulation and baroclinicity during the second half of the twentieth century. They found that many of the models were not able to capture the sign of these changes. Of the models that were able to, the miroc3_2_medres and miroc3_2_hires were particularly good. We have also examined the annual cycle of trends in the baroclinicity in these two models. The miroc3_2 hires model reproduces the annual cycle reasonably well but has trends that are about half or less of the observed; miroc3_2_medres has trends which are much smaller again.
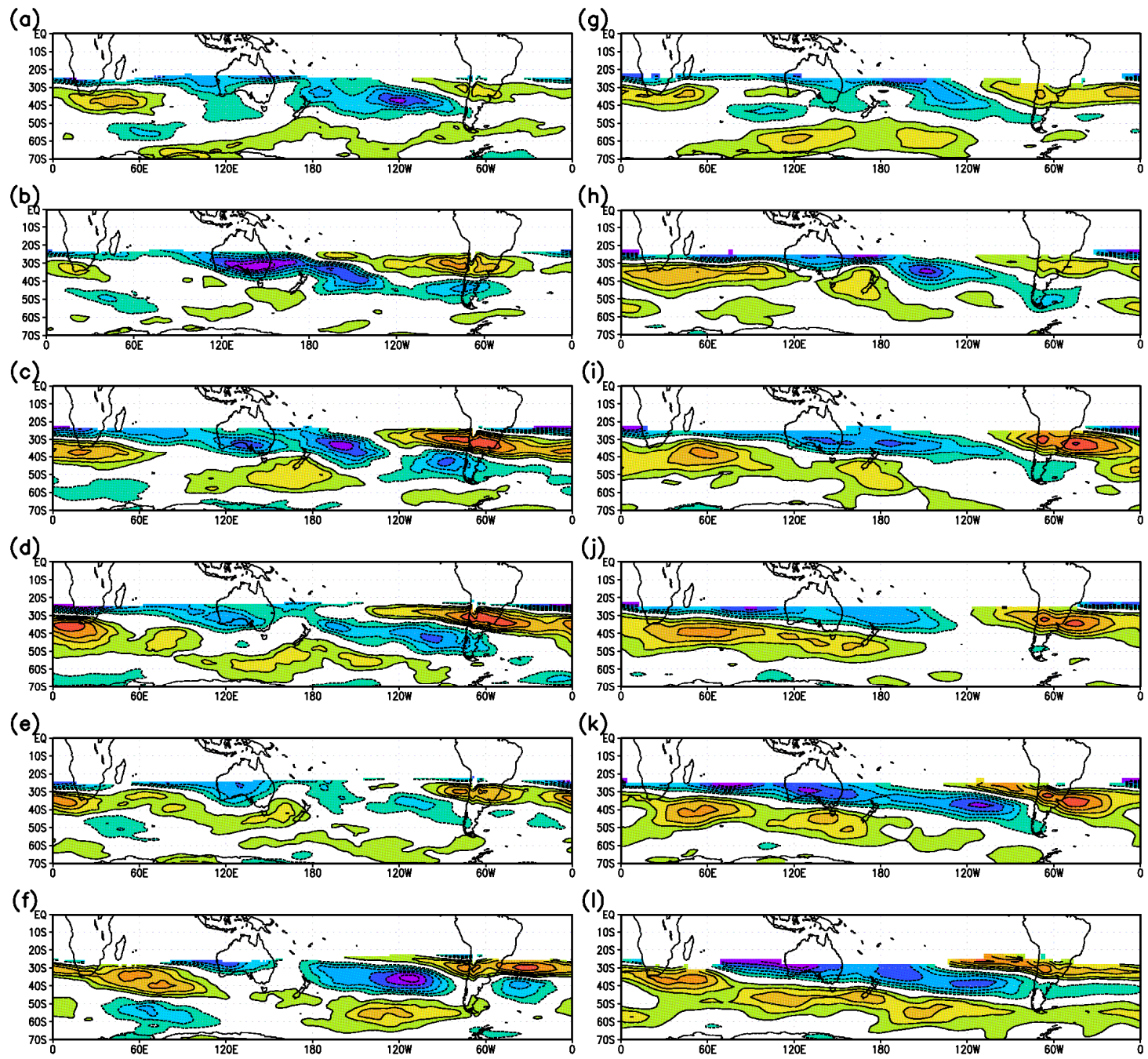

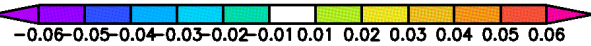

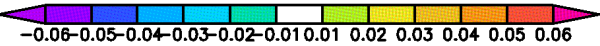

Figure 3. Trends in the May - October Phillips instability criterion ( $\mathrm{ms}^{-1}$ per year), over the period 2001 - 2100, from the miroc3_2 hires model ((a) - (f)) for the SRESA1B scenario, and from the miroc3_2_medres model $((\mathrm{g})-(\mathrm{l}))$ for the SRESA2 scenario.

Figure 3 shows the trends in the Phillips criterion over the period 2001 - 2099 for the months of May October from the miroc3_2_hires model under the SRESA1B scenario (Figure 3(a) - (f)) and from the 
Frederiksen et al., Observed and projected changes in the annual cycle of Southern Hemisphere...

miroc3_2_medres model under the SRESA2 scenario (Figure 3(g) - (1)). The trends shown are generally significant at the $99 \%$ level or $95 \%$ level. In both cases, the models predict negative trends upstream and over the southern half of Australia at latitudes between $25 \mathrm{~S}-35 \mathrm{~S}$. These negative trends can be as negative as $0.06 \mathrm{~ms}^{-1}$ per year. Positive trends approaching $0.06 \mathrm{~ms}^{-1}$ per year are seen further poleward. These trends are about half those seen in the reanalysis observations during the twentieth century. During the twentieth century, these models also tend to display trends which are about half those for the reanalyzed observations. This suggests that under both future scenarios the rate of reduction in baroclinic instability near $30 \mathrm{~S}$, observed in the twentieth century, will continue into the twenty first century. By implication, we might expect to see similar reductions in the growth rate of storms over the next fifty years as has occurred, over the last fifty years (Frederiksen et al., 2010) over southern Australia. Similar patterns of trends are seen in the SRESB1 scenario for both models, and for the SRESA1B for the miroc3_2_medres.

(a)

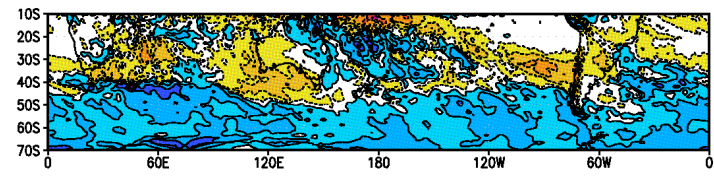

(b)

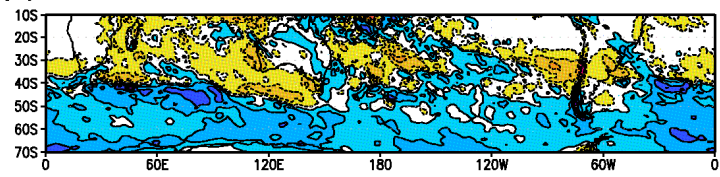

(c)

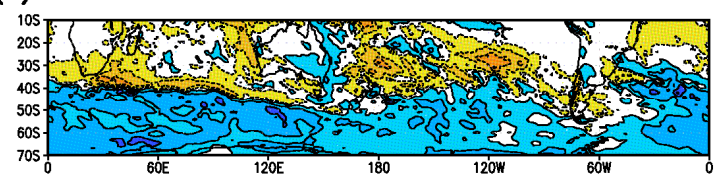

(d)

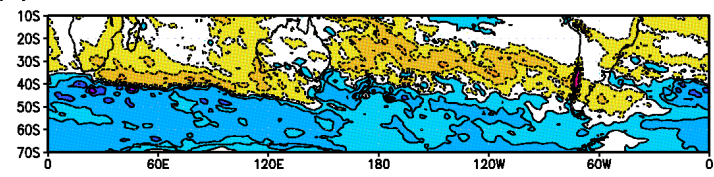

(e)

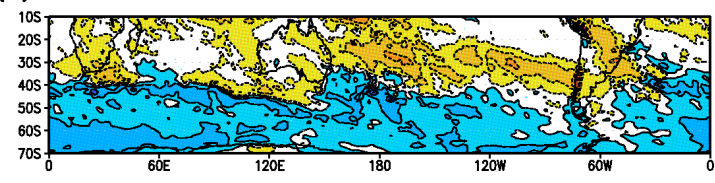

(f)
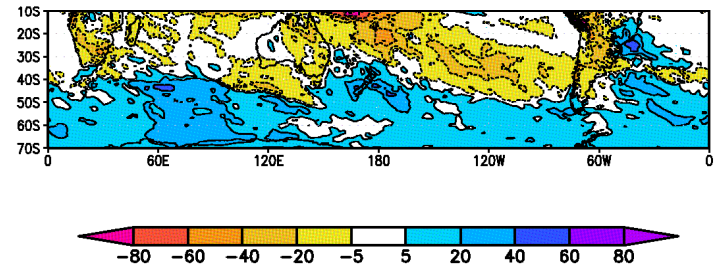

(g)

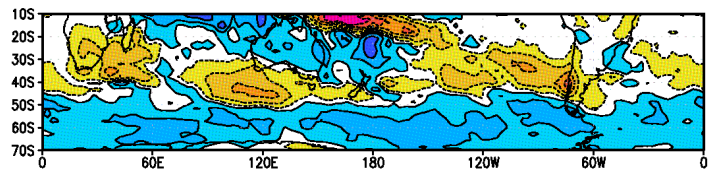

(h)

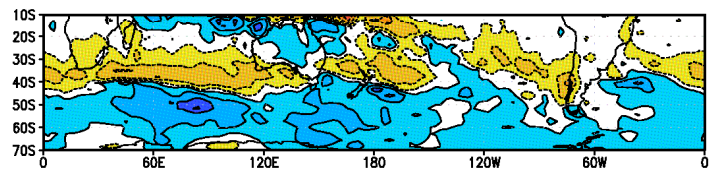

(i)

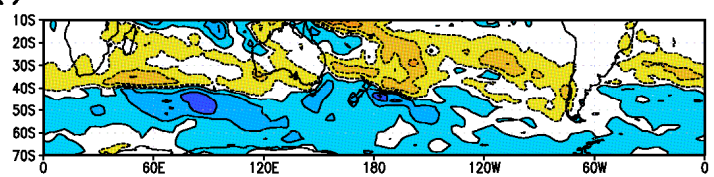

(j)

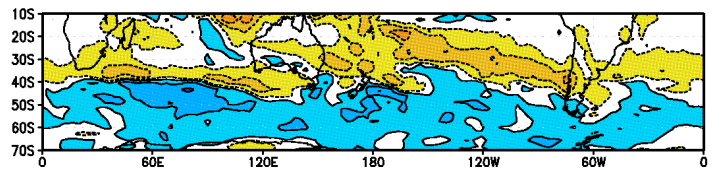

(k)

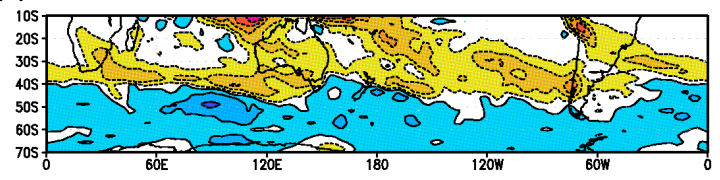

(1)
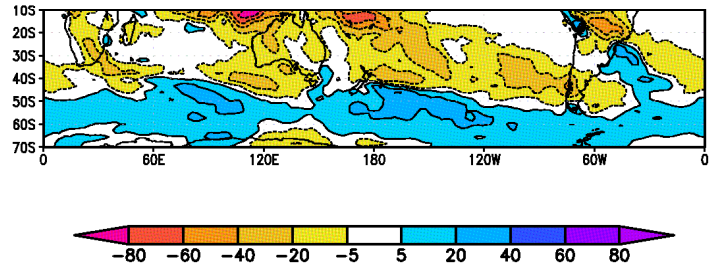

Figure 4. Differences in rainfall ( $\mathrm{mm}$ per month) for the months May to October, between the periods (2080-2099) and (1980-1999) from the miroc3_2_hires model ((a) - (f)) for the SRESA1B scenario, and from the miroc3_2_medres model $((\mathrm{g})$ - (l)) for the SRESA2 scenario.

The impact of these trends in the baroclinic instability on Southern Hemisphere rainfall can be seen in Figure 4. This shows the differences in the average rainfall between the periods (2080-2099) and (1980-1999), for the months May to October, corresponding to the trends shown in Figure 3 for the miroc3_2_hires (Figure 
Frederiksen et al., Observed and projected changes in the annual cycle of Southern Hemisphere...

4(a) - (f)) and miroc3_2_medres (Figure 4(g) - (l)) models. In all months, there are generally reductions in rainfall in a zonal band and north of about $40 \mathrm{~S}$; increases in rainfall are generally seen south of $40 \mathrm{~S}$. This is consistent with the corresponding negative/positive trends in baroclinic instability seen at these latitudes and the consequent expected decrease/increase in storm development. Differences in rainfall varies between $40 \mathrm{~mm}$ to $+40 \mathrm{~mm}$. Over SWWA and southeastern Australia there are reductions in rainfall in all months with differences exceeding $-20 \mathrm{~mm}$ in some months, especially over SWWA, where the largest declines occur during May, June and July.

\section{DISCUSSION AND CONCLUSIONS}

We have examined the changes in the annual cycle of SH baroclinic instability for the period 1950-1999, and find that there are significant negative trends in a mid-latitude zonal band in all months; a similar band of significant positive trends occurs further poleward. This decrease/ increase in baroclinic instability would tend to decrease/ increase storm formation at these latitudes over this period. This is consistent with the study of Frederiksen et al. (2011c) where it is shown that there is a reduction of the intensity of the subtropical storm track and an increase in the polar storm track particularly in autumn and spring. Future projections of trends in baroclinicity, during May to October, over the period 2001-2099 show a similar pattern of negative and positive trends. The impact of these trends results in decreased rainfall in a band between 10S and 40S, adversely affecting southern Australia; poleward of 40S, there are generally increases in rainfall.

\section{ACKNOWLEDGMENTS}

We acknowledge the modeling groups, the Program for Climate Model Diagnosis and Intercomparison and the World Climate Research Program's Working Group on Coupled Modeling for their roles in making available the CMIP3 multi-model dataset. This research is partly supported by the Australian Climate Change Science Program of the Australian Department of Climate Change S, and the West Australian Department of Environment and Conservation under the Indian Ocean Climate Initiative Stage 3.

\section{REFERENCES}

Bates, B.C., Hope, P. and Ryan, B. (2008), Key findings from the Indian Ocean Climate Initiative and their impact on policy development in Australia, Climatic Change, 89, 339-354.

Frederiksen, C.S. and Frederiksen, J.S. (1992), Northern hemisphere storm tracks and teleconnection patterns in primitive equation and quasigeostrophic models, J. Atmos. Sci., 49, 1443-1458.

Frederiksen, C.S., Frederiksen, J.S., Sisson, J.M. and Osbrough, S.L. (2011a), Changes and projections in Australian winter rainfall: Anthropogenic forcing and internal variability, Int. J. Climate Change Impacts and Responses, 2, 143-162.

Frederiksen, C.S., Frederiksen, J.S., Sisson, J.M. and Osbrough, S.L. (2011b), Australian winter circulation and rainfall changes and projections, Int. J. Climate Change Strategies and Management, 3, 170-188.

Frederiksen, J. S. and Frederiksen, C.S. (2005), Decadal Changes in Southern Hemisphere Winter Cyclogenesis. CSIRO Marine and Atmospheric Research Paper No. 002, 35pps.

Frederiksen, J.S. and Frederiksen, C.S. (2007), Interdecadal changes in southern hemisphere winter storm track modes, Tellus, 59A, 599-617.

Frederiksen, J.S., Frederiksen, C.S., Osbrough, S.L. and Sisson, J.M. (2010), Causes of changing Southern Hemispheric weather systems, Chapter 8, Managing Climate Change, Eds. I. Jupp, P. Holper and W. Cai, CSIRO publishing, pp85-98.

Frederiksen, J.S. and Frederiksen, C.S. (2011), Twentieth century winter changes in Southern Hemisphere synoptic weather modes, Adv. Meteorol. (in press)

Frederiksen, J.S., Frederiksen, C.S., Osbrough, S.L. and Sisson, J.M. (2011c), Changes in Southern Hemisphere Rainfall, Circulation and Weather Systems. Modsim11, submitted.

Meehl, G.A. et al. (2007), The WCRP CMIP3 multimodel dataset: A new era in climate change research, Bull. Amer. Meteor. Soc., 88, 1383-1394, doi:10.1175/BAMS-88-9-1383.

Nicholls, N. (2007), Detecting, understanding and attributing climate change, Australian Greenhouse Office Publication, 26pp.

Phillips, N.A. (1954), Energy transformations and meridional circulations associated with simple baroclinic waves in a two-level, quasi-geostrophic model. Tellus, 6, 273-286.

Randall, D.A., et al. (2007), Climate models and their evaluation, in Climate Change 2007: The Physical Science Basis. Contribution of Working Group I to the Fourth Assessment Report of the Intergovernmental Panel on Climate Change, edited by S. Solomon et al., pp. 589-662, Cambridge Univ. Press, Cambridge, U. K. 